\title{
AGROECOLOGIA COMO ENFOQUE DA EXTENSÃO RURAL PÚBLICA: DESAFIOS E APRENDIZADOS A PARTIR DO VALE DO RIO DOCE
}

AGROECOLOGY AS AN APPROACH FOR PUBLIC RURAL EXTENSION: CHALLENGES AND LEARNING BASED ON THE DOCE RIVER VALLEY

AGROECOLOGÍA COMO ENFOQUE DE LA EXTENSIÓN RURAL PÚBLICA: DESAFÍOS Y APRENDIZAJE DEL VALLE DEL RÍO DOCE

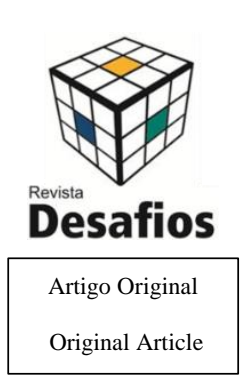

Filipe Fernandes de Sousa*1, Douglas Mansur da Silva² ${ }^{2}$, Marcelo Leles Romarco de Oliveira $^{3}$, Eugênio Martins de Sá Resende ${ }^{4}$

${ }^{1}$ Doutorando em Extensão Rural, Universidade Federal de Viçosa, Viçosa/MG, Brasil

${ }^{2}$ Professor Associado II, Universidade Federal Fluminense, Volta Redonda/RJ, Brasil

${ }^{3}$ Professor Associado I, Universidade Federal de Viçosa, Viçosa/MG, Brasil

* Correspondência: Departamento de Economia Rural, Avenida Purdue, s/n ${ }^{o}$, Campus Universitário, Edifício

Edson Potsch Magalhães, Viçosa /MG, e-mail: filipe_fernandes08@yahoo.com.br

Artigo recebido em 07/01/2020 aprovado em 04/06/2020 publicado em 31/10/2020.

\section{Resumo}

É objetivo deste artigo desvelar os elementos norteadores das chamadas públicas com enfoque agroecológico no Brasil, mais precisamente as contribuições para as práticas extensionistas, visando arrolar avanços e desafios para a institucionalização desse enfoque nos serviços de extensão rural, tendo como base empírica um contrato executado no médio rio Doce, Minas Gerais. Para tanto, lançou-se mão da análise documental, da revisão bibliográfica e da observação participante. Conclui-se que, mesmo condicionadas pelos instrumentos normativos, as chamadas públicas possibilitaram integrar novos atores como promotores e beneficiários dos serviços, constituir ações dialógicas, e fortalecer as articulações territoriais. Por outro lado, sugere-se que maiores esforços devem ser direcionados ao refinamento institucional, a fim de sintonizar esses elementos com as necessidades locais.

Palavras-chave: Transição agroecológica; Desenvolvimento rural; Políticas Públicas.

\section{Abstract}

The objective of this paper is to reveal the guiding elements of public calls with an agroecological approach in Brazil, more precisely the contributions to extension practices, aiming to list advances and challenges for the institutionalization of this approach in rural extension services, having as an empirical basis a contract executed in middle Doce River, Minas Gerais. There were held documentary analysis, literature review and participant observation for this end. It is concluded that, notwithstanding the limits imposed by the normative instruments, the public calls made it possible to integrate new actors, such as promoters and recipients of the services, establish dialogical action and strengthen territorial connections. However, it is suggested that greater effort should be directed towards institutional refinement in order to synchronize these elements with the local demands.

Keywords: Agroecological transition; Rural development; Public policy.

Resumem 
El objetivo de este artículo es revelar los elementos rectores de las llamadas públicas con un enfoque agroecológico en Brasil, más precisamente las contribuciones a las prácticas de extensión, con el objetivo de enumerar los avances y desafios para la institucionalización de este enfoque en los servicios de extensión rural, teniendo como base empírica un contrato ejecutado en Río Doce medio, Minas Gerais. Para este fin, utilizamos el análisis documental, la revisión de la literatura y observación participante. Se concluye que, aun condicionado por los instrumentos normativos, las llamadas públicas permitieron integrar a nuevos actores como promotores y beneficiarios de los servicios, constituir acciones de diálogo y fortalecer las articulaciones territoriales. Por otro lado, se sugiere que se dediquen mayores esfuerzos al refinamiento institucional para alinear estos elementos con las necesidades locales.

Palavras clave: transición agroecológica; Desarrollo rural; Políticas públicas.

\section{INTRODUÇÃO}

A análise das concepções e práticas de desenvolvimento adotadas ao longo da trajetória da Assistência Técnica e Extensão Rural - Ater no Brasil, mostra três períodos distintos que se enquadram como marcos referenciais para compreender essa trajetória. $\mathrm{O}$ primeiro, caracterizado como "humanismo assistencialista" (1948-1962), o segundo chamado de difusionismo produtivista" (19631984) e o terceiro caracterizado como "humanismo crítico" (1985-1989) (Rodrigues, 1997; Braga e Futemma, 2015).

Em que pese as críticas aos modelos adotados em cada período, foi de fato a partir da “modernização conservadora" (Delgado, 2001), promovida no período do difusionismo produtivista, que houve a intensificação dos questionamentos, principalmente em função das evidências das consequências socioambientais negativas e da marcante diferenciação social do campo brasileiro (Caporal e Dambrós, 2017). Além disso, parte dessas críticas foram direcionadas ao Estado, que se tornou protagonista do processo de modernização através do fornecimento de recursos financeiros (crédito orientado), que serviu de incentivo aos agricultores para aderirem aos pacotes tecnológicos à época difundidos (Delgado, 2001).

Foram as evidências dessas contradições e das consequências socioambientais negativas que estimularam o surgimento de um movimento de crítica e contestação aos modelos até então adotados, e de construção de um enfoque alternativo. Inicialmente denominado de agriculturas alternativas, esse movimento, a partir de um maior embasamento teórico, passa posteriormente a ser denominado agroecológico (Nierdele et al., 2019; Schmitt, 2013). Paulatinamente, além da construção de práticas alternativas junto aos agricultores familiares, essa ampla rede de articulação, através da participação em arenas de discussão e de tomadas de decisões, passa a introduzir tal concepção de desenvolvimento na elaboração de diversas políticas públicas (Nierdele et al., 2019). Dessa forma, o Estado e os serviços de Ater ainda continuam tendo papéis centrais, porém agora como indutores da transição do modelo vigente, para outro, que se pretende socioambientalmente mais equilibrado.

Porém, é apenas a partir de 2003, com o advento de um governo popular e com a abertura para a ampla participação da sociedade 
civil organizada, que o Estado passa a encarar com mais afinco a possibilidade de institucionalização da agroecologia como enfoque orientador dos processos de desenvolvimento rural e, consequentemente, como eixo norteador dos serviços de Ater no País (Diesel e Dias, 2016). Nesse novo cenário uma diversidade de atores foi mobilizada, no intuito de construir a Política Nacional de Assistência Técnica e Extensão Rural PNATER, onde a agroecologia passou a ser o enfoque norteador.

Evidentemente, essa possibilidade também fez emergir novos movimentos de contestação, agora formados por grupos que não consideram importante promover mudanças de direcionamento na Ater no sentido proposto, e que também possuem influencia na construção das políticas públicas. Assim, as tensões e conflitos existentes nesse percurso evidenciam tanto a falta de consenso entre os atores envolvidos nas dinâmicas de desenvolvimento rural, quanto as limitações inerentes a concepção agroecológica de desenvolvimento, o que torna sua institucionalização ainda ambígua e incerta (Diesel e Dias, 2016).

Diante do conflituoso caminho percorrido e considerando os avanços alcançados nos marcos legais e normativos para o campo da agroecologia, considera-se um marco histórico a elaboração de chamadas públicas ${ }^{1}$ com enfoque agroecológico, realizada pelo extinto Ministério do Desenvolvimento Agrário-MDA, no ano de 2013 (Brasil, 2013).
Essas chamadas, comumente denominadas de "Ater Agroecologia" são produtos de lutas históricas e consequentemente as que mais incorporaram demandas dos movimentos sociais e organizações do campo, que defendem um novo modelo de desenvolvimento para o rural brasileiro.

Sugere-se que devido ao pouco tempo de execução dos serviços de Ater por meio de chamadas públicas, e principalmente das chamadas orientadas pelo enfoque agroecológico, poucas são as literaturas acadêmicas que buscam analisá-las a fim de compreender os seus novos aportes. Quais as modificações promovidas sobre os serviços de Ater? Quais as suas contribuições para a consolidação da agroecologia como paradigma da extensão rural? Essas são apenas algumas perguntas que orientaram a elaboração deste artigo.

Portanto, visando enriquecer os debates sobre a extensão rural contemporânea, é objetivo deste artigo desvelar os elementos inovadores da chamada pública com enfoque agroecológico e compreender as consequências dessas inovações para a prática extensionista, identificando os avanços e desafios para a institucionalização da agroecologia como enfoque norteador da extensão rural pública.

$\mathrm{O}$ artigo está dividido em cinco seções além desta parte introdutória. Na seção seguinte é realizada uma breve análise da construção e inserção da agroecologia nos serviços de Ater no País, que será sucedida pela análise dos

\footnotetext{
${ }^{1}$ Segundo o decreto ${ }^{\circ} 7.215 / 2010$, a contratação de serviços de Assistência Técnica e Extensão Rural - ATER deverá ser antecedida pela chamada pública, com objetivo de classificar propostas técnicas apresentadas pelas entidades interessadas na execução.
} 
métodos que subsidiaram a elaboração deste artigo. Posteriormente são evidenciados os elementos que caracterizaram a chamada pública $\mathrm{n}^{\circ} 13 / 2013$, denominada de Ater Agroecologia, os quais são confrontados com os elementos empíricos, na seção seguinte. Por fim, são tecidos comentários em forma de conclusão.

\section{Agroecologia e Extensão rural: das agriculturas alternativas às chamadas públicas}

No Brasil, as consequências socioambientais negativas decorrentes do modelo de desenvolvimento adotado pelo Estado para o campo brasileiro, aliadas ao contexto social de redemocratização do País, fizeram emergir em meados da década de 1980 diversos grupos de crítica, contestação e construção de um modelo alternativo (Nierdele et al., 2019; Schmitt, 2013), até então denominados de grupos de agriculturas alternativas. Esses grupos foram responsáveis por promover intensos debates sobre as consequências do modelo em voga para a população do campo e para o meio ambiente, e também por construir, a partir de experiências consolidadas pelos agricultores, alternativas às técnicas e tecnologias até então disseminadas.

Frutos dessas mobilizações e contestações, consideram-se importantes conquistas na esfera pública, a proibição dos venenos organoclorados e a aprovação da lei de agrotóxicos (lei 7.802/1989), que representam os momentos mais importantes no enfrentamento aos impactos da "modernização" da agricultura brasileira (Caporal e Petersen,
2012) e também de inserção nos espaços de construção de políticas públicas, ambos no final da década de 1980.

Com efeito, é a partir desse contexto de mobilização de atores e de construção de alternativas técnicas, tendo os grupos de agriculturas alternativas e os agricultores familiares como protagonistas, que a agroecologia emerge no Brasil, se afirma após os anos 1990 como uma referência teórica e conceitual (Caporal e Petersen, 2012; Sambuich et al., 2017; Schmitt, 2013) e em sintonia com os aporte teóricos e metodológicos internacionais busca se estabelecer enquanto movimento, ciência e prática (Gliessman, 2018; Wezel et al., 2009).

Diante desse quadro de engajamento social, da socialização das experiências exitosas e de um processo de amadurecimento teórico, surge no final da década de 1990, a primeira tentativa de institucionalização da agroecologia como enfoque norteador dos serviços de Ater promovidos por órgãos públicos. Com efeito, as primeiras experiências de Ater governamental com enfoque agroecológico foram colocadas em prática no Rio Grande do Sul pela EMATER/RS, no período de 1999 a 2002 (Caporal e Petersen, 2012). É válido citar que essa iniciativa se consolidou no estado do RS em um período conturbado para a extensão rural no País, tendo em vista que a década de 1990 é marcada pelo aprofundamento da crise econômica e da implementação de uma política de cunho neoliberal, onde os serviços de Ater passaram a ser desestruturados (Telles et al., 2017). Entretanto, essa experiência seminal mais tarde passou a servir de modelo para a 
tentativa de institucionalização da agroecologia nas políticas de Ater no âmbito federal.

Passada uma década da experiência da EMATER/RS, é apenas a partir de 2003, com o início do governo de Luiz Inácio Lula da Silva que surgem tendências de mudanças no direcionamento dos serviços de Ater do País. Nesse período, ganha força a construção de uma proposta de reestruturação dos serviços de Ater, com a participação de organizações da sociedade civil, movimentos sociais e prestadoras oficiais públicas (Telles et al., 2017). É nesse período, em especial durante o processo participativo de construção da Política Nacional de Assistência Técnica e Extensão Rural - PNATER, que se identifica a necessidade de uma extensão rural agroecológica $^{2}$ e definitivamente a agroecologia passa a ser tema central nas discussões sobre Ater no âmbito federal (Caporal e Dambrós, 2017; Diesel e Dias, 2016).

Por outro lado, esse novo período, distante de significar um momento de consenso político na história da Ater no País, resultou em um aprofundamento dos intensos embates ideológicos e disputas de projetos, os quais visavam influenciar as agendas do governo para o desenvolvimento rural. Ou seja, a realidade era de grupos diversos com interesses divergentes tentando influenciar as tomadas de decisões a fim de satisfazer as suas prioridades (Diesel e Dias, 2016). É também o momento que se evidencia uma clara contradição existente nas ações governamentais, que buscava consolidar a coexistência de dois modelos antagônicos de desenvolvimento, de um lado o agronegócio e do outro a agricultura familiar (Caporal e Petersen, 2012; Diesel e Dias, 2016).

É inserido nesse contexto macropolítico que ocorre a aprovação do principal instrumento de regulamentação dos serviços de Ater no País, a lei 12.188/2010, comumente denominada lei de Ater. Evidentemente, ela se materializa com as marcas desses conflitos e desfigurada dos elementos centrais que as caracterizavam nos primórdios de sua construção coletiva. Ou seja, a agroecologia que deveria ser o eixo norteador dos processos de desenvolvimento, ou o tema de convergência entre as diversas políticas, conforme desenhado no início da nova gestão do País, passa a ser parte de ações pontuais de programas de governo (Diesel e Dias, 2016).

Entretanto, pode se considerar um avanço importante para as organizações do campo agroecológico, por ocasião da institucionalização da lei de Ater, o incentivo do Estado a participação dessas organizações na execução dos serviços de Ater, por meio da contratação dos serviços após o chamamento público e seleção das organizações. Evidentemente, isso não significou uma mudança de direcionamento, porém institucionalizou a descentralização dos serviços de Ater, onde novos atores passaram a ser protagonistas, não apenas os órgãos públicos (Braga e Futemma, 2015).

\footnotetext{
${ }^{2}$ Sobre o conceito de Extensão Rural Agroecológica, ver Caporal (1998).
} 
Nos anos posteriores, um novo marco reitera os conflitos existentes no âmago do Estado, mas que dessa vez favorece os atores engajados na institucionalização de um novo enfoque. Fruto da mobilização e pressão da sociedade civil, em especial da Articulação Nacional de Agroecologia - ANA, e como pauta reivindicatória da IV Marcha das Margaridas ${ }^{3}$, em 2012 é instituída por meio do decreto $\mathrm{n}^{\circ}$ 7.794, a Política Nacional de Agroecologia e Produção Orgânica-PNAPO (Coradin e Souza, 2017; Diesel e Dias, 2016; Sambuich et al., 2017), a qual tem como objetivo "integrar, articular e adequar políticas, programas e ações indutoras da transição agroecológica e da produção orgânica e de base agroecológica...” (Brasil, 2012, p. 1). É por meio desse decreto, que se passa a dispor de um dispositivo legal para orientar e regulamentar a Ater e diversos outros programas direcionados ao campo da agroecologia (Coradin e Souza, 2017; Diesel e Dias, 2016).

Por consequência, em 2013 são lançadas as primeiras chamadas públicas direcionadas para a promoção da agroecologia e da produção orgânica no País, orientadas pela PNAPO. Essas chamadas se consolidam como um dos maiores avanços para a agroecologia em termos de políticas públicas. As chamadas $n^{\circ}$ 12/2013 direcionadas para as regiões Norte, Nordeste e Centro Oeste e a n¹3/2013 direcionada para as Regiões Sul e Sudeste, são as que mais incorporaram em seus editais as reivindicações históricas da sociedade civil, em especial dos movimentos agroecológico e de mulheres (Telles, Arantes e Freitas, 2017), somadas à ampla participação dos movimentos sociais e sindicais nas diversas etapas de construção. Portanto considera-se essencial compreender quais as contribuições dessas chamadas para a extensão rural, e consequentemente o que favorecem e propiciam para os processos de desenvolvimento rural.

\section{METODOLOGIA}

É necessário destacar que esse artigo possui uma grande contribuição da vivência do primeiro autor enquanto coordenador de um contrato de Ater firmado entre uma Organização não Governamental, o Centro Agroecológico Tamanduá - CAT e o extinto Ministério do Desenvolvimento Agrário MDA, no período de agosto de 2014 à dezembro de 2017. O lote 31, que corresponde a delimitação territorial desse contrato, foi composto por 20 municípios, localizados na região leste do estado de Minas Gerais, na macrorregião da Bacia do Rio Doce, na porção média desse território. A estimativa era de que 500 Unidades de Produção Familiares - UPF’s fossem beneficiadas.

Portanto, compreende-se que houve inicialmente uma imersão na realidade pesquisada e posteriormente uma análise teórica sobre esse universo. Dito isso, esta pesquisa se aproxima essencialmente do caráter da pesquisa-ação (Tripp, 2005). Ou seja, esse é um processo que segue um ciclo, onde "se aprimora

\footnotetext{
${ }^{3}$ Mobilização nacional que articula mulheres trabalhadoras do campo, das águas e da floresta em busca de seus direitos.
} 
a prática pela oscilação sistemática entre agir no campo da prática e investigar a respeito dela. Planeja-se, implementa-se, descreve-se e avalia-se uma mudança para a melhora de sua prática, aprendendo mais, no correr do processo, tanto a respeito da prática quanto da própria investigação" (Tripp, 2005, p. 446). Dessa forma, compreende-se que por ter havido interação com os grupos sociais e atuação diretamente no contexto especifico analisado, houve a coleta de dados por meio da técnica da observação participante (Marconi e Lakatos, 2011).

Como técnica de pesquisa também se lançou mão da análise documental, explorando três relatórios públicos elaborados pela contratada e enviada à contratante, e três documentos referentes à chamada pública. Portanto, foram analisados o edital da chamada pública e os seus referidos resultados, e três relatórios anuais produzidos pela contratada nos anos 2015, 2016 e 2017. Houve a triangulação dos dados através da consulta ao Sistema informatizado de Ater - SIATER, onde são disponibilizadas diversas informações sobre os contratos executados e vigentes sob a coordenação da Secretaria Especial de Agricultura Familiar e do Desenvolvimento Agrário - SEAD, do governo federal.

A análise do conteúdo coletado se deu em três fases, organizadas cronologicamente (a pré-análise, a exploração do material e a inferência/interpretação dos dados), como sugerido por Bardin (2011). Na pré-análise ocorreram o mapeamento dos diversos assuntos relacionados à Ater e o delineamento das regras para a fase seguinte, a exploração. A exploração se deu a partir da divisão dos elementos analisados em categorias, por meio da similaridade semântica. Dessa forma as categorias temáticas foram originadas e se apresentam na forma de tópicos ao longo das próximas seções. Por fim, realizou-se a inferência e interpretação do conteúdo a partir dos referenciais teóricos, que deram sentido aos achados, com base na triangulação dos dados documentais e empíricos.

\section{PERSPECTIVAS DAS CHAMADAS PÚBLICAS COM ENFOQUE AGRoECOLÓgico}

\section{Sobre o Objeto e a distribuição geográfica}

Para fins de análise, as discussões realizadas na sequência serão reportadas à chamada $\mathrm{n}^{\circ} 13 / 2013^{4}$, projetada para os estados das regiões Sul e Sudeste do País. Objetivamente, essas chamadas tinham como proposta "consolidar e ampliar processos de promoção da agroecologia existentes, para promoção do desenvolvimento local/territorial e de seus processos organizativos, considerando seus diferentes processos de transição e as diretrizes da Política Nacional de Agroecologia e Produção Orgânica - PNAPO” (Brasil, 2013, p.5).

Com efeito, pretendia-se por meio dessas chamadas intensificar e/ou consolidar os processos de transição dos sistemas

\footnotetext{
${ }^{4}$ É possível extrapolar as discussões apresentadas para a chamada $\mathrm{n}^{\circ} 12 / 2013$, tendo em vista que o objeto é o mesmo, apenas os indicadores, metas e lotes são especificidades de cada chamada.
} 
agroecológicos nas Unidades Familiares de Produção- UFP. Portanto, direcionada para promover mudanças nas bases produtivas, a previsão era beneficiar por meio desta chamada 23.510 UFP's pelo prazo de 36 meses (Brasil,
2013). Dessa forma, foram agrupados 36 lotes compostos por diversos municípios, distribuídos nas regiões de abrangência da chamada (Gráfico 1).

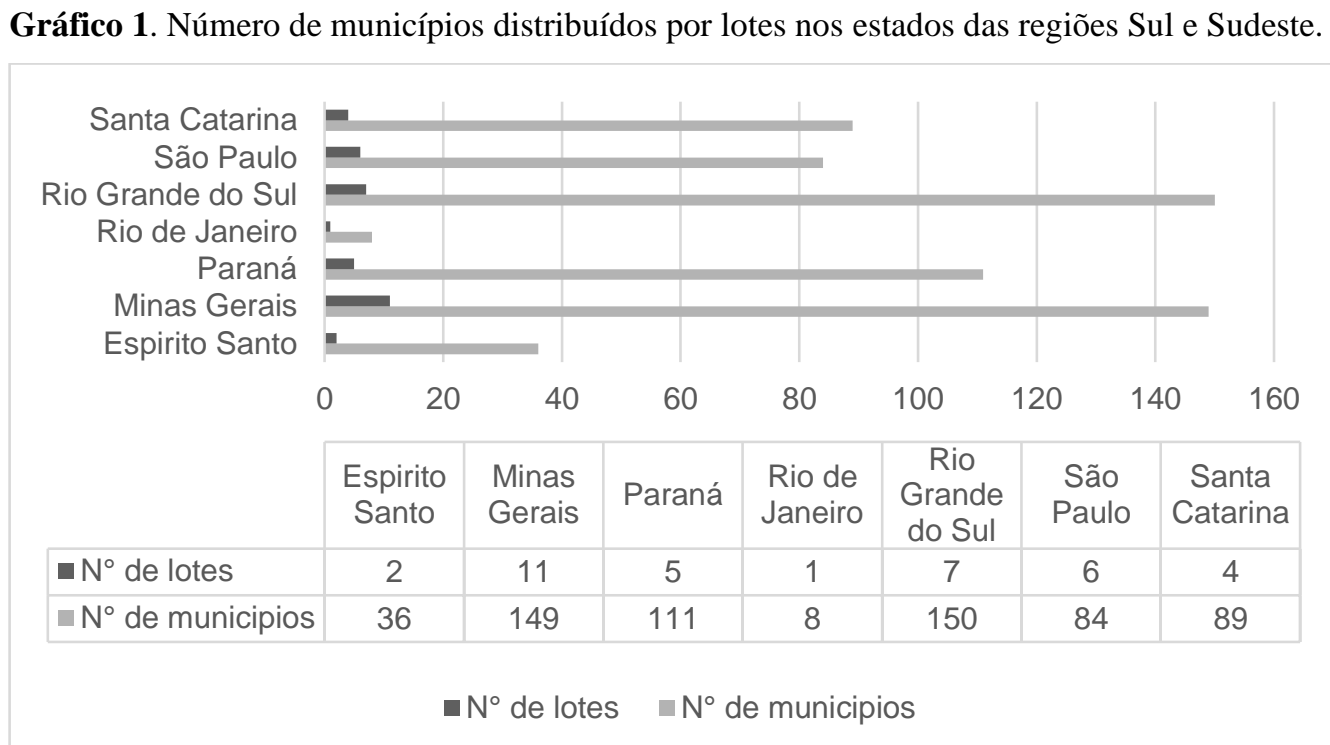

Fonte: Elaborado pelos autores com base em Brasil (2013).

Observa-se que no estado de Minas Gerais - MG houve maior distribuição em termos de número de lotes (11), seguido pelo Rio Grande do Sul - RS (7) e por São Paulo - SP (5). Por outro lado, ao considerar o número de municípios distribuídos por lote, há uma inversão, estando o maior número de municípios beneficiados localizados no RS, seguido por MG e Paraná. Essa divisão evidencia uma tendência apresentada para os estados da região Sul, onde houve menor divisão dos estados e consequentemente o aumento no número de municípios por lote. Cabe mencionar que conforme descrito no edital, os lotes foram "organizados considerando aspectos regionais e a existência de processos organizativos, [...] além de critérios de proximidade, área, número de agricultores familiares e a existência de organizações econômicas da agricultura familiar (cooperativas com DAP jurídica)" (Brasil, 2013, p. 6).

Por outro lado, ao analisar a situação dos lotes após a avaliação pelo MDA (Tabela 1), evidencia-se uma redução do número de lotes preenchidos, e consequentemente no número de municípios e UPF's beneficiadas.

Diversos lotes tiveram organizações selecionadas e contratadas para a execução dos serviços, entretanto observa-se também a existência de lotes onde não foram efetivadas as contratações, seja pela desclassificação das organizações proponentes frente aos critérios 
estabelecidos, pela ausência de entidades proponentes, ou também pela própria desistência das organizações anteriormente selecionadas. Ao confrontar o resultado final da chamada pública com a lista de contratos estabelecidos pelo MDA provenientes desta chamada, sugere-se que no estado do ES houve a desistência de uma entidade, tendo em vista que para esse estado não consta nenhum contrato firmado entre o MDA e entidade executora de Ater, que reflete na redução de $100 \%$ em relação à proposta inicial. Em consequência, nota-se que para o estado de SP também houve redução no número de municípios atendidos, a partir da redução em $20 \%$ dos lotes pretendidos inicialmente, assim como em MG onde observou-se a redução de $18 \%$ em relação ao número inicial.

Tabela 1. Situação dos lotes após a aplicação dos critérios definidos no chamamento público e porcentagem de redução.

\begin{tabular}{lccc} 
Estado & Contratado & $\begin{array}{c}\text { Não } \\
\text { contratado* }\end{array}$ & $\begin{array}{c}\text { Redução } \\
(\%)\end{array}$ \\
\hline ES & 0 & 2 & 100 \\
MG & 9 & 2 & 18 \\
PR & 5 & 0 & 0 \\
RJ & 1 & 0 & 0 \\
RS & 7 & 0 & 0 \\
SP & 5 & 1 & 20 \\
SC & 4 & 0 & 0 \\
\hline
\end{tabular}

* Não contratação por desistência, não habilitação das entidades ou por não haver apresentação de propostas. Fonte: Elaborado pelos autores com base em Brasil (2013).

$$
\text { É importante destacar que a }
$$
participação de organizações da sociedade civil nessas chamadas envolve alto grau de complexidade, por existir diversos condicionantes que são balizados pelos postulantes antes de se submeterem aos chamamentos públicos. Cada organização possui as suas particularidades de bens e infraestruturas disponíveis, formas organizacionais internas, limites geográficos de atuação, além das particulares prioridades de ação, que podem aproximá-las ou afastá-las tanto de uma prestação de serviço junto ao Estado, quanto dos próprios princípios da PNATER, que são os instrumentos de orientação da Ater, conforme evidenciam Braga e Futemma (2015).

Analisando especificamente o número de UPF's beneficiadas pela chamada, observase a mesma tendência encontrada para o número de municípios beneficiados, onde MG aparece em primeiro, seguido pelo RS e pelo PR (Gráfico 2). É expressiva a quantidade de UPF's que deveriam ser beneficiadas no estado de MG, onde das 23.510 disponíveis no edital para todos os estados das duas regiões, somente em MG se concentrava 8.700 unidades, que equivale à $37 \%$ do total previsto. Por outro lado, no Rio de Janeiro, apenas 500 UPF's deveriam ser beneficiadas, que equivale à aproximadamente $2 \%$ do total previsto.

A ordem observada para o número de UPF's beneficiadas nos estados, continuou após a contratação dos serviços pelo MDA, onde MG, RS e PR foram os estados mais beneficiados. Porém, observa-se ampla redução no número de beneficiários em relação ao proposto inicialmente, conforme consta no edital. A redução mais significativa ocorreu em MG, onde observou-se uma diminuição de $43 \%$ da quantidade proposta inicialmente. Destacase que em alguns lotes há diferenças 
consideráveis no número de beneficiários propostos no edital e na quantidade contida nos contratos, sugerindo uma possível adequação desse número na ocasião do acordo entre as partes envolvidas. Além disso, conforme evidenciado na tabela anterior, em dois lotes não houve postulantes ao chamamento público. Por esse mesmo motivo, observa-se que para o estado de SP também houve redução de $13 \%$ do número de beneficiários, assim como em um dos lotes do estado do ES. Neste último, houve redução de $100 \%$ do número de beneficiários, evidenciado pela ausência de contratos realizados pelo MDA com organizações desse estado.

Gráfico 2. Número de atendimento de UPF's proposto no edital e efetivado por meio de contrato, nos estados da região Sul e Sudeste.

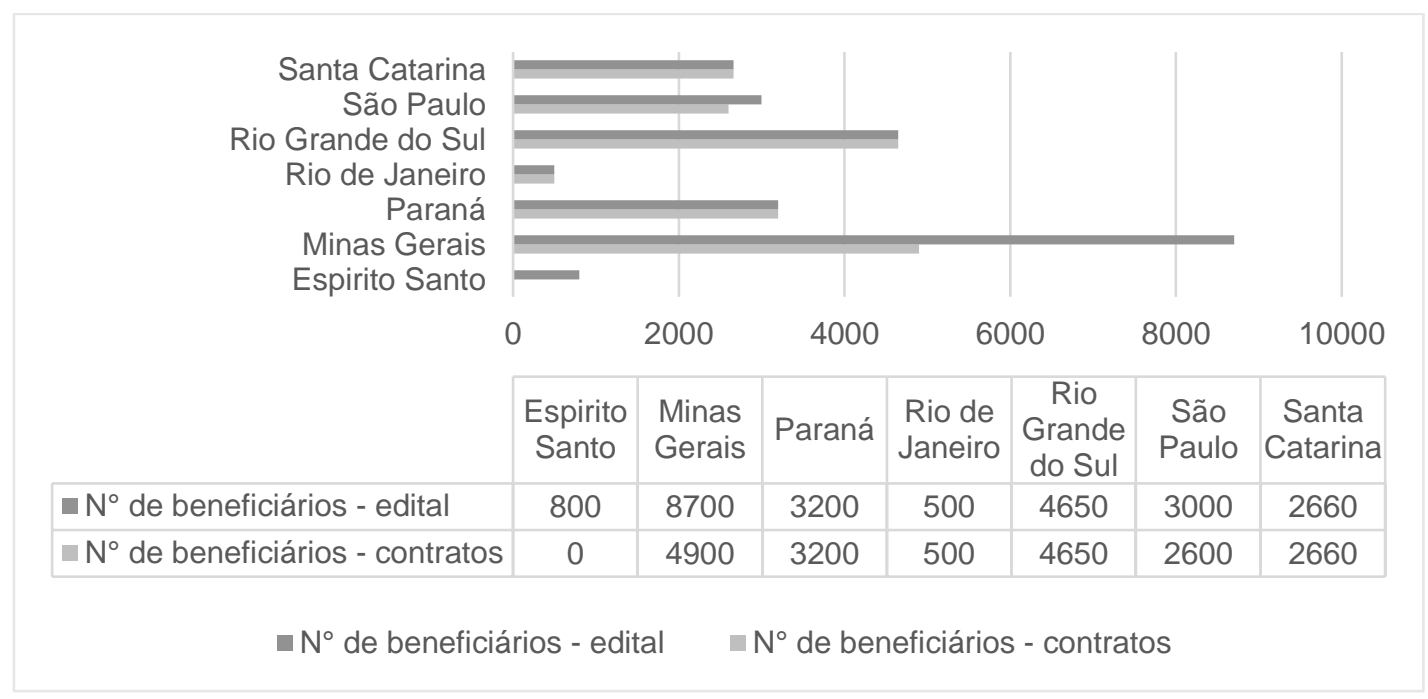

Fonte: Elaborado pelos autores com base em Brasil (2013).

Por fim, fato que desperta atenção é a ausência das Empresas Estaduais de Ater no chamamento público, onde predominou a contratação de organizações da sociedade civil. Não foram encontradas informações que nos permitissem afirmar com precisão os fatos e/ou as circunstâncias que desembocaram nesse cenário. Entretanto, especificamente sobre a Empresa de Assistência Técnica e Extensão Rural de Minas Gerais - EMATER/MG, observou-se o direcionamento dos esforços na participação das chamadas que objetivaram o fortalecimento das cadeias produtivas do leite e do café, produtos de relevância na agropecuária mineira (EMATER/MG, 2017). Diante desse fato, sugere-se que a impossibilidade de sobreposição ${ }^{5}$ de contratos aliado ao formato ${ }^{6}$ da chamada direcionada à agroecologia, tenham influenciado na tomada de decisão resultando

\footnotetext{
${ }^{5}$ Execução de dois ou mais contratos na mesma área, com o mesmo público.

${ }^{6}$ A chamada de Agroecologia privilegiou as atividades coletivas em detrimento às atividades individuais, onde o foco é a construção coletiva do conhecimento, embora as atividades individuais se façam presentes e sirvam como complementação da ação pedagógica.
} 
na ausência da empresa no chamamento público.

\section{Sobre o protagonismo de novos(?) atores sociais}

É nas chamadas de Ater agroecologia que se observa a incorporação de diversas demandas históricas da sociedade civil, principalmente a valorização de grupos historicamente invisibilizados nas políticas públicas. Por meio de tópicos normativos e de indicadores de desempenho presentes no edital, incorporou-se estratégias para o favorecimento e protagonismo dos jovens e das mulheres rurais, sendo que para esse último grupo as ações foram mais objetivas. Três aspectos deveriam ser atendidos pelas entidades executoras dos serviços de Ater direcionados especificamente às mulheres: o número de mulheres rurais beneficiárias; o montante de recurso financeiro alocado para promoção de ações específicas com as mulheres e; o percentual de mulheres integrantes da equipe técnica.

Conforme o item 4.6 do edital, o público beneficiário deveria “observar uma participação de, no mínimo, 50\% de mulheres no total de beneficiários do contrato, ao longo dos 36 meses" (Brasil, 2013, p. 5). É importante destacar que a comprovação desse número poderia ocorrer por meio da verificação in loco pelos fiscais dos contratos, mas principalmente por meio da observação do nome e sexo dos beneficiários cadastrado no SIATER. Fator relevante que merece destaque é que esse protagonismo das mulheres não inviabilizava a participação dos outros membros familiares nas atividades, ao contrário, o foco das ações deveria ser o núcleo familiar. E para tanto, houve inclusive a flexibilização da assinatura dos atestes (comprovantes de atividades), que poderiam ser assinados por qualquer membro, inclusive pelos filhos, desde que fossem apresentados documentos comprobatórios de pertencimento ao núcleo familiar e possuísse maioridade.

Em complemento a essas ações, segundo o item 4.5 do mesmo edital pelo menos $30 \%$ dos recursos deveriam "ser destinados a atividades específicas com as mulheres rurais" (Brasil, 2013, p. 5). Esse item, necessariamente condicionava as entidades executoras a adotar mecanismos metodológicos de captação de demandas e construção coletiva de ações vinculadas a esse público. Por outro lado, fazia emergir também a necessidade de promover contínuas capacitações com as equipes técnicas, para torná-las sensíveis ao processo de construção com um grupo historicamente invisibilizado pelas ações extensionistas.

Conforme afirmam Telles et al., (2017), essas ações inovadoras caminham em sentido oposto ao papel histórico dos serviços de Ater proposto pelo Estado, que contribuiu para reforçar o papel das mulheres na esfera doméstica desconsiderando o seu papel econômico e produtivo, quando focado apenas o cuidado com a casa e a família (Telles et al., 2017). Não obstante, conforme afirmam os autores, essas ações significam também o reflexo dos embates promovidos por grupos de mulheres organizadas, presentes nos espaços de construção e de controle dessas políticas 
públicas, induzindo os formuladores das políticas à atenderem suas demandas.

Impulsionado pela necessidade de promover ações com as mulheres para além da esfera doméstica e também para promover o protagonismo feminino em um campo de trabalho predominantemente masculino, o item 10.3 do edital condiciona a entidade executora a promover a inserção de quantidade razoável de técnicas mulheres, de ensino técnico e superior, na composição da equipe. Nesse item é citado que "a equipe técnica deve ser composta por no mínimo $30 \%$ de mulheres" (Brasil, 2013, p. 9). Efetivamente, essa ação possibilitaria o estabelecimento de uma nova forma de abordagem por parte dos extensionistas e suas organizações, assim como na metodologia aplicada às mulheres rurais, se distanciando de formas historicamente reproduzidas, determinadas pela divisão sexual do trabalho, conforme afirma Spetch (2017).

Com efeito, observa-se na chamada a preocupação de promover ações afirmativas para públicos historicamente alijados das ações dos serviços de extensão rural no Brasil. Nas ações promovidas junto aos jovens e mulheres rurais, esse público quase sempre foi relegado das esferas produtivas e preteridos pelos serviços de extensão, que focalizavam as ações nos homens, os "chefes de família" (Telles et al., 2017).

Dessa forma, uma Ater que se pretenda inclusiva necessita, por meio de métodos diferenciados, promover ações indutoras do protagonismo para os grupos historicamente excluídos dos processos. Tal protagonismo, então, é algo a ser alcançado por meios ancorados na realidade sociocultural dos territórios, dificilmente alcançados através de direcionamentos homogêneos ou métodos únicos. A realidade sociocultural deve ser a base de afloramento desses meios. Fato que se pretendeu alcançar por meio dos condicionantes observados nas chamadas públicas analisadas.

\section{Sobre os aportes metodológicos e a presença} de um "novo agente técnico"

Nota-se na chamada um esforço direcionado a qualificação e diferenciação dos serviços ofertados para os beneficiários da política pública. Conforme consta no edital,

[...] Do ponto de vista metodológico a chamada de Ater Agroecologia busca apoiar organizações que atuam na construção do conhecimento agroecológico, rompendo com a lógica do extensionismo difusionista que tem como base a Ater individual, em que os/as técnicos/as são os/as detentores/as do conhecimento e das soluções técnicas que serão transmitidas aos agricultores/as (BRASIL, 2013, p. 16).

Com base nessa orientação, percebe-se uma mudança significativa a partir da substituição dos questionários aplicados em chamadas anteriores pelo instrumento de "Caracterização dos Agroecossistemas", que previa uma diversidade de análise conjunta da UFP, relacionados a produção e também de relações sociais, a exemplo da análise do trabalho das mulheres na unidade de produção (Telles et al., 2017).

Em relação à equipe técnica, percebe-se $\mathrm{o}$ incentivo à multidisciplinaridade para compreensão da complexidade do campo e, por meio das estratégias de desenvolvimento local pautadas na agroecologia, promover as ações necessárias. $\mathrm{O}$ edital previa a contratação de 
uma equipe composta por técnicos de nível médio e superior, inclusive de outras áreas do conhecimento que não apenas das ciências agrárias, desde que obedecidas as proporções previstas no edital. Todavia, necessariamente essa equipe deveria ser composta por no mínimo 30\% de mulheres. Além disso, a presença de profissionais formados em escolas famílias agrícolas e em cursos de educação do campo eram fatores valorizados na chamada, refletindo no aumento da pontuação das organizações participantes no chamamento.

Seguramente, uma importante incorporação na chamada pública, que é recorrente nas equipes das ONG's do campo agroecológico, foi a presença do agricultor(a) formador(a) atuante no campo junto a outros agricultores. A participação desse ator na equipe era facultativa e quando presente deveria substituir um profissional de nível médio. Entretanto, o agricultor formador deveria possuir experiência em atividades de Ater, na produção agroecológica, orgânica ou no agroextrativismo sustentável, assim como em espaços e fóruns de gestão e controle social (Brasil, 2013).

Mais do que contar com a presença de um "agricultor", essa inovação propõe na estrutura da equipe um agente para a reorientação dos métodos e práticas extensionistas. Fundamentada nas perspectivas teóricas da ação dialógica (Freire, 1983), essa inovação visa essencialmente o reconhecimento e valorização dos saberes locais, a promoção da troca com os saberes técnicos e o rompimento com o ethos extensionista enraizado no período do "difusionismo produtivista" (Dias, 2007).
Esse ator, o qual caracterizamos como "um novo agente técnico", mais do que agricultor e para além de um agente local, é um agente histórico, portador de conhecimento tácito, capaz de promover mudanças expressivas na emblemática relação técnico-agricultor.

\section{ATER AGROECOLOGIA NO MÉDIO RIO DOCE: QUAIS APRENDIZADOS?}

\section{Sobre o fortalecimento das redes e articulações locais}

Aspecto importante no processo de execução da proposta técnica foi a inserção de diversos atores sociais na sua condução, por meio de uma articulação local. Com efeito, embora o CAT tenha sido a organização contratada, responsável legal do contrato, criouse uma comissão local, formada por diferentes organizações de abrangência regional, a qual foi denominada de comissão política do Ater, com a função de promover o planejamento e a execução de ações a partir dos consensos criados na diversidade de racionalidades.

Não foram encontrados nos documentos consultados, em especial na chamada pública, nenhuma condicionante à contratada de formalização e constituição de algum tipo de comissão. No caso analisado essa articulação foi composta por seis organizações: 1) o CAT enquanto proponente e representante legal, 2) o sindicato dos trabalhadores rurais de Governador Valadares STR/GV; 3) o movimento dos pequenos agricultores - MPA; 4) o movimento de mulheres camponesas - MMC; 5) o núcleo de agroecologia de Governador Valadares NAGÔ, ligado à Universidade Federal de Juiz 
de Fora campus Governador Valadares, e; 6) a cooperativa regional de economia solidária da agricultura familiar agroecológica CRESAFA. O diagrama a seguir ilustra essa articulação.

Diagrama 1. Articulação política para execução do Ater Agroecologia no médio rio Doce/MG.

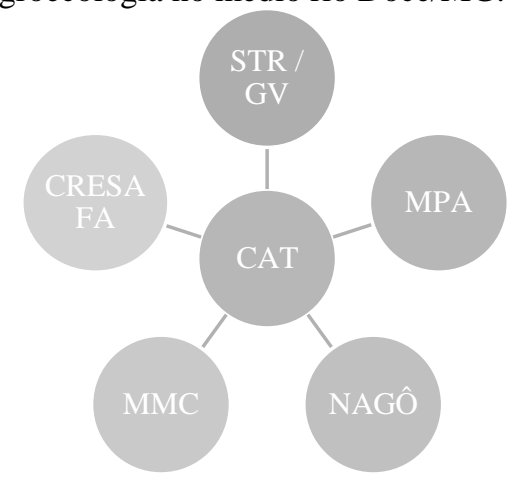

Fonte: Elaborado pelos autores.

Dois desdobramentos provenientes dessa articulação merecem destaque. O primeiro foi a integração de diversos saberes e experiências, direcionados para a construção dos planejamentos estratégicos e tomadas de decisões. Houve a integração dos saberes técnicos-acadêmicos com os saberes locais, construídos sobre realidades distintas, direcionados para a construção de alternativas para o desenvolvimento do território. O segundo foi o envolvimento desses diferentes atores nas fases de execução da proposta em campo. Cada organização possui sua rede de interação e espaços de atuação territorial, favorecendo a permeabilidade dos representantes técnicos nesses espaços. Em várias comunidades dos municípios previstos no lote da chamada onde o CAT não promovia ações regulares, o apoio das outras organizações foi fundamental, para "abrir as portas" para a entrada desse novo ator territorial.

Além disso, o diálogo entre os diferentes atores proporcionou a captação de diversas demandas e criação de consensos em prol de um interesse comum, qual seja o fortalecimento e expansão da agroecologia no território. Portanto essa articulação local para o apoio a execução de um projeto de Ater, pode ser considerado um importante aprendizado, tendo em vista que esse é um dos principais problemas nas execuções de projetos e chamadas públicas em diversos territórios, conforme apontam Caporal e Dambrós (2017). A aglutinação das diversas forças territoriais se apresenta como um importante vetor para o alcance dos objetivos propostos pelas chamadas públicas.

Sobre a multidisciplinaridade, relação de gênero e presença do "novo agente técnico"

A composição da equipe técnica contou majoritariamente com a presença de profissionais enquadrados na área de ciências agrárias, fato que se caracteriza como um distanciamento da promoção de uma Ater essencialmente multidisciplinar (Quadro 1).

Quadro 1. Formação da equipe técnica atuante na chamada pública.

\begin{tabular}{|c|c|}
\hline FORMAÇãO & GÊNERO \\
\hline Agronomia & Feminino \\
\hline Agroecologia & Masculino \\
\hline Técnico em Agroecologia & Feminino \\
\hline Zootecnia & Feminino \\
\hline Biologia & Masculino \\
\hline Técnico em Agropecuária & Feminino \\
\hline Agricultor Formador & Masculino \\
\hline
\end{tabular}

Fonte: Elaborado pelos autores 
Entretanto, há de se considerar que o objeto da chamada era promover mudanças nas bases sóciotécnicas, por meio da adoção de práticas agroecológicas, o que na prática reflete na demanda pelos profissionais dessa área.

Percebe-se que a equipe foi composta de acordo com os condicionantes presentes na chamada pública, que determinavam a presença mínima de um profissional das agrárias para dois de outras áreas. Por outro lado, esse fato também evidencia a existência da possibilidade de inclusão dos profissionais de outras áreas, caso houvesse necessidade e/ou interesse.

Outro condicionante presente no edital e que foi incorporado pela contratada foi o protagonismo das mulheres na equipe técnica, inclusive para além do mínimo previsto no edital. Percebe-se que $57 \%$ da equipe era composta por mulheres, excedendo o mínimo de $30 \%$. As principais contribuições, para além do favorecimento à luta contra as desigualdades de gênero, foram a mudança na relação entre a equipe técnica e as mulheres rurais, a ampliação da sensibilidade para entendimento e captação de demandas, e a ampliação das capacidades técnicas para o planejamento de ações direcionadas a esse público. A presença das mulheres na equipe possibilita a compreensão de especificidades presentes nesse universo, por diversas vezes incompreendidas por outros sujeitos, principalmente do sexo masculino.

Conforme demonstrado em seções anteriores, uma inovação proposta pela chamada pública foi a possibilidade de possuir como integrante da equipe, um "agricultor formador", o qual esteve presente na equipe composta pelo CAT. A principal função foi de facilitar o diálogo entre técnicos e agricultores de forma horizontal, procurando valorizar o saber local, em detrimento do diálogo vertical, impositor do saber científico, vastamente praticado por agentes extensionistas. A análise documental permitiu observar que esse "novo agente técnico", pertencia a região, possuía vasto conhecimento sobre a cultura local e experiência prática sobre produção agroecológica, além de ampla participação em espaços e fóruns de discussões sobre agricultura familiar e agroecologia no médio rio Doce. A sua presença também esteve em consonância com o edital que previa a substituição de um técnico de nível médio, ao optar pela sua presença.

Portanto, buscou-se por meio desses atores, estabelecer relações mais horizontais e inclusivas socialmente, visando a superação do caráter verticalizado e da racionalidade hegemônica, recorrentes nos serviços de Ater (Rambo et al., 2015), valorizando a contraracionalidade presente essencialmente na figura do agricultor formador.

\section{Sobre os desafios para o acesso ao rol de políticas públicas}

Enfatiza-se que embora a chamada pública delineasse em linhas gerais a necessidade de inserção dos agricultores familiares nas diversas políticas públicas existentes, principalmente o acesso aos mercados institucionais, observou-se que nenhum desses temas foi priorizado e discutido especificamente nas atividades realizadas durante a execução do contrato. Certamente o programa de aquisição de alimentos -PAA, o 
programa nacional de alimentação escolar PNAE, assim como o programa nacional de fortalecimento da agricultura familiar PRONAF, são fundamentais para o desenvolvimento socioeconômico e, consequentemente, favorecem a melhoria na qualidade de vida das famílias envolvidas.

Porém, fatores locais influenciam diretamente o funcionamento dessas políticas, e que por diversas vezes estão bem distantes da governança das organizações contratadas. Percebe-se que a conjuntura política local, o interesse dos setores públicos e o nível de organização dos agricultores familiares, tencionam localmente o funcionamento dessas políticas públicas. Portanto, são desajustes complexos e de difícil resolução diante dos engessamentos estabelecidos nas chamadas públicas.

Para ilustrar esses desafios, um exemplo será destacado. $\mathrm{O}$ acesso a declaração de aptidão ao PRONAF - $\mathrm{DAP}^{7}$, se configurou como um entrave importante para a execução da chamada pública, e sugere-se que também seja um problema para o acesso e funcionamento de outras políticas, como o PNAE, tendo em vista que a posse do documento é condicionante para acessá-las. No estado de Minas Gerais os principais emissores da DAP são, a Empresa de Assistência Técnica e Extensão Rural de Minas Gerais - EMATER/MG por meio de seus escritórios locais e os Sindicatos locais conveniados. Porém, três municípios do território não possuíam escritório da EMATER conveniado com a prefeitura e nem sindicato indicado para emissão do documento, o que impossibilitou a participação dos agricultores desses municípios como beneficiários da chamada pública, e provavelmente restringe o acesso às outras políticas direcionadas para a agricultura familiar.

Em outros municípios o atendimento precário ou o uso político do serviço, fez com que um número significativo de agricultores não tivesse acesso ao documento. Entretanto, é necessário destacar que esses são problemas pontuais, tendo em vista que em outros municípios foi possível promover ações conjuntas entre esses diversos atores - empresa contratada e órgãos emissores - para a emissão da DAP, embora esse fato não se configure como uma regra. Porém, é evidente o desajuste nos mecanismos institucionais para a emissão das DAP's, que consequentemente dificulta o acesso dos agricultores às políticas públicas existentes.

\section{Sobre o dilema da governança e da inovação}

Conforme demonstrado em tópicos anteriores, a lei de Ater como dispositivo regulamentador das práticas extensionistas fez emergir, a partir da sua vigência, uma nova modalidade de prestação de serviço, por meio da descentralização, efetivada através das chamadas públicas (Braga e Futemma, 2015). Essas chamadas passaram a ser acessíveis tanto

\footnotetext{
${ }^{7}$ Documento oficial do Governo Federal para identificação dos agricultores familiares, incluindo assentados da reforma agrária, quilombolas, indígenas entre outros de acordo com a Lei Federal 12.188/2010, que os possibilitam acessar diversas políticas públicas.
} 
às organizações governamentais quanto às ONG's e empresas privadas, desde que em consonância aos diversos pré-requisitos estabelecidos nos editais.

Em função do funcionamento desse novo dispositivo, duas consequências importantes ocorrem para a execução dos serviços, conforme observado no caso empírico: uma relacionada ao processo de governança por parte do Estado, que influencia diretamente a outra, qual seja, a obstacularização das capacidades inovadoras das organizações executoras. Em primeiro lugar, as chamadas públicas aumentam o controle do Estado sobre os serviços, tendo em vista que essas chamadas possuem critérios prédefinidos, como número de beneficiários, objetivo, prazo e territórios definidos, que por diversas vezes são incompatíveis com a flexibilidade e aprendizado local valorizado nos processos de transição agroecológica (Brasil, 2013; Diesel e Dias, 2016).

Em segundo, a partir do momento de celebração do contrato, as organizações passam a figurar na lista de prestadores de serviços enquadrados sobre a égide da lei de contratos e licitações do governo federal (lei 8.666/1993), que enquadra todos os serviços contratados, desde construções a fornecimento de bens, de forma homogênea. Porém, o conjunto de dispositivos normativos previstos na lei normalmente não está sintonizado com a necessidade de potencialização da capacidade de criação e inovação para enfrentamento dos problemas locais, características inerentes às organizações da sociedade civil, e que são essenciais para a o processo de transição agroecológica.

Para as chamadas públicas de Ater Agroecologia houve tentativas de superação de alguns entraves operativos, por meio dos direcionamentos propostos pelo Comitê de Assistência Técnica e Extensão Rural, do Conselho Nacional de Desenvolvimento Rural Sustentável - CONDRAF e pelo Grupo de Trabalho Operacional/GTO, espaço de controle social criado em função das chamadas de Ater Agroecologia, também pertencente ao Comitê acima referenciado (Telles et al., 2017). Porém, tais alinhamentos comumente esbarravam nas amarras jurídico-burocráticas dos mecanismos de controle do Estado.

Sugere-se que um importante caminho para incidir sobre os descompassos no âmbito jurídico, é a adequação institucional às normativas da Lei 13.019/2014, conhecida como Marco Regulatório das Organizações da Sociedade Civil - MROSC, em vigor desde janeiro de 2016, e que "[...] institui normas gerais para as parcerias entre a administração pública e organizações da sociedade civil..." (Brasil, 2014, p. 1).

Destarte, embora esse seja um caminho importante, ressalta-se a necessidade de promover a sintonia entre os entraves evidenciados pelas organizações em função da execução dos contratos e os modelos de governança do Estado, para que as capacidades inovadoras sejam potencializadas e os “engessamentos" institucionais não sejam os maiores entraves às transformações à serem construídas nos territórios. 


\section{CONSIDERAÇÕES FINAIS}

A análise das últimas chamadas publicas direcionadas para o fortalecimento da agroecologia e da agricultura orgânica no Brasil, revelaram a incorporação de diversas pautas historicamente demandadas pela sociedade civil organizada, sobretudo dos movimentos de mulheres, que podem ser compreendidas como avanços importantes para a Ater no País. Identificou-se nas chamadas públicas a inserção de metas que favoreceram o protagonismo dos jovens e mulheres, como a destinação de recursos específicos e a reestruturação dos métodos historicamente utilizados nos serviços de Ater convencionais.

Outra importante incorporação nas chamadas públicas foi a presença do agricultor formador, um agente de transformação da relação técnico-agricultor, que permitiu estabelecer uma relação horizontalizada e dialógica, buscando superar o caráter verticalizado e a racionalidade hegemônica do conhecimento técnico-científico. Além disso, a possibilidade de ter integrantes de outras áreas e obrigatoriamente a presença feminina, também se apresentaram como marcadores importantes, indicando uma reformulação no perfil técnico de atuação nos serviços de Ater.

Esses avanços indicam fortemente como as chamadas públicas com enfoque agroecológico modificou a práxis extensionista ao favorecer o reconhecimento e diálogo com a pluralidade de conhecimentos e grupos sociais existentes, ao facilitar o diálogo entre os atores e o intercâmbio de saberes, e não favorecer, na prática, apenas o "chefe da família", mas sim o núcleo familiar. Como efeito secundário dessas inovações, identificou-se o fortalecimento das redes de organizações locais, possibilitando o engajamento de diversos atores em função de um objetivo comum, fato que se apresentou como um dos vetores do sucesso da execução do contrato analisado.

Como desafios, constatou-se que ainda é preciso avançar e romper com os obstáculos inerentes ao próprio funcionamento dos instrumentos normativos, para que o formato dessa chamada pública possa servir de modelo para a institucionalização de uma extensão rural agroecológica. Um deles é o enquadramento das organizações na lei de licitações e contratos da União, que envolve um conjunto de burocracias que não estão em sintonia com as necessidades de inovação geradas na prática nos territórios. Além disso, identificou-se também a necessidade de ajustes nas normas de emissão das DAP's, para favorecer a inclusão de beneficiários, não somente para essa política pública analisada, mas também para outras tão relevantes para o desenvolvimento rural, como o PNAE. Ajustes são importantes para que os descompassos do funcionamento desses instrumentos não se tornem entraves aos serviços de Extensão Rural e, consequentemente, ao processo de transição agroecológica.

\section{AGRADECIMENTO}

Ao apoio da FAPEMIG no desenvolvimento deste trabalho, através da concessão de bolsa de pesquisa do primeiro autor. 


\section{REFERÊNCIAS}

BARDIN, L. Análise de conteúdo. São Paulo: Edições 70, 2011.

BRAGA, A. C. R.; FUTEMMA, C. Pluralidade da assistência técnica e extensão rural: pública, privada e de organizações da sociedade civil. Ruris, v. 9, n. 2, p. $239-268,2015$.

BRASIL. Ministério do Desenvolvimento Agrário. Chamada pública conjunta INCRA/MDA para seleção de entidades executoras de assistência técnica e extensão rural para promoção da agricultura familiar agroecológica, orgânica e agroextrativista para regiões Sul e Sudeste, 2013. $\overline{12.188,} 2010$.

Presidência da República. Lei no Presidência da República. (2012). Decreto ${ }^{\circ}$ - 7.794, 2012.

Presidência da República. (2014). Lei $\mathrm{n}^{\circ} 13.019,2014$.

CAPORAL, F. R. Em defesa de um plano nacional de transição agroecológica: compromisso com as atuais e nosso legado para as futuras gerações. In: S. Sauer e M. V. Balestro (Eds.), Agroecologia e os desafios da transição agroecológica, $2^{\circ}$ ed., p. 261-304, São Paulo: Expressão popular, 2013.

CAPORAL, F. R. La extensión agraria del sector público ante los desafíos del desarrollo sostenible: el caso de Rio Grande do Sul, Brasil (Tese de Doutorado, Universidade de Córdoba), 1998.

CAPORAL, F. R. Lei de Ater: Exclusão da Agroecologia e outras armadilhas. Cadernos de agroecologia, v. 6, n. 2, p. 1-7, 2011.

CAPORAL, F. R.; DAMBRÓS, O. Extensão Rural Agroecológica: experiências e limites. Redes - Santa Cruz do Sul, v. 22, n. 2, p. $275-297,2017$.

CAPORAL, F. R.; PETERSEN, P. Agroecologia e políticas públicas na américa latina: o caso do Brasil. Agroecología, v. 6, n. 1, p. 63-74, 2012.

CORADIN, C.; SOUZA, R. S. Agroecologia por contrato, é possível? Revista NERA, v. 37, n. 1, p. 105-128, 2017.
DELGADO, G. C. Expansão e modernização do setor agropecuário no pós-guerra: um estudo da reflexão agrária. Estudos avançados, v. 15, n. 43, p. 157-172, 2001.

DIAS, M. M. As mudanças de direcionamento da política nacional de assistência técnica e extensão rural (PNATER) face ao difusionismo. Revista Oikos, v. 18, n. 2, p. 11-21, 2007.

DIESEL, V.; DIAS, M. M. The Brazilian experience with agroecological extension: a critical analysis of reform in a pluralistic extension system. The Journal of Agricultural Education and Extension, v. 22, n. 5, p. 415-433, 2016.

EMATER - Empresa de Assistência Técnica e Extensão Rural de Minas Gerais. Chamada Pública para assistência técnica permite atendimento diferenciado aos agricultores familiares, 2015.

FREIRE, P. Extensão ou comunicação? ( $7^{\text {a }}$ ed.). São Paulo: Paz e Terra, 1983.

GLIESSMAN, S. Defining Agroecology. Agroecology and Sustainable Food Systems, v. 42 , n. 6 , p. $599-600,2018$

GLIESSMAN, S. Agroecologia: processos ecológicos em agricultura sustentável ( $2^{\circ} \mathrm{ed}$.). Porto Alegre: UFRGS, 2001.

MARCONI, M. A.; LAKATOS, E. M. Metodologia científica. São Paulo, Atlas, 2011.

NIERDELE, P. A.; SABOURIN, E.; SCHMITT, C. J.; ÁVILA, M. L.; PETERSEN, P.; ASSIS, W. S. A trajetória brasileira de construção de políticas públicas para a agroecologia. Redes - Santa Cruz do Sul, v. 24, n. 1, p. 270 - 291, 2019.

RAMBO, J. R.; DINIZ, R. F.; HESPANHOL, A. N.; SANT'ANA, A. L. Políticas públicas de extensão rural no brasil contemporâneo: avanços e desafios à construção do desenvolvimento rural sustentável nos estados de Minas Gerais e Mato Grosso. $53^{\circ}$ Congresso da SOBER. Sociedade brasileira de economia, administração e sociologia rural. Paraíba, Brasil, 2015.

RODRIGUES, C. M. Conceito de seletividade de políticas públicas e sua aplicação no contexto da política de extensão rural no Brasil. 
Cadernos de Ciência e Tecnologia, v. 14, n. 1, p. 113 - 154, 1997.

SAMBUICH, R. H. R.; SPÍNOLA, P. A. C.; MATTOS, L. M.; ÁVILA, M. L.; MOURA, I. F. M.; SILVA, A. P. M. Análise da construção da política nacional de agroecologia e produção orgânica no Brasil, 2017.

SCHMITT, C. J. Transição agroecológica e desenvolvimento rural: um olhar a partir da experiência Brasileira. In: S. Sauer e M. V. Balestro (Eds.), Agroecologia e os desafios da transição agroecológica, $2^{\circ}$ ed., p. 173-198, São Paulo: Expressão popular, 2013.

SPETCH, A. A. Estratégias de incorporação da perspectiva de gênero na Política Nacional de Assistência Técnica e Extensão
Rural. Seminário Internacional Fazendo Gênero 11 e 13th Women's Worlds Congress. Santa Catarina - Brasil, 2017.

TELLES, L.; ARANTES, A. O.; FREITAS, A. F. Mulheres, agroecologia e a trajetória da ater no Brasil. Seminário Internacional Fazendo Gênero 11 e 13th Women's Worlds Congress. Santa Catarina - Brasil, 2017.

TRIPP, D. Pesquisa-ação: uma introdução metodológica. Educação e Pesquisa, v. 31, n. 3, p. 443-466, 2005.

WEZEL, A.; BELLON, S.; DORÉ, T.; FRANCIS, C.; VALLOD, D.; DAVID, C. Agroecology as a science, a movement and a practice: a review. Agronomy for Sustainable Development, v. 29, n. 4, p. 503-515, 2009. 